\title{
Serum Erythropoietin (ESF) Levels and Erythroid Progenitors (CFU-Es) of Patients with Chronic Myeloproliferative Disorders
}

\author{
Yukitaka Fukushima, Ikuo Miura, Toru Takahashi, \\ Mitsuyuki Fukuda, Kosaku Yoshida, Akihiko \\ Yamaguchi and Akira B. MiUra \\ The Third Department of Internal Medicine, Akita \\ University School of Medicine, Akita 010
}

\begin{abstract}
Funushima, Y., Miura, I., Takahashi, T., Fukuda, M., Yoshida, K., Yamaguchi, A. and Miura, A.B. Serum Erythropoietin (ESF) Levels and Erythroid Progenitors (CFU-Es) of Patients with Chronic Myeloproliferative Disorders. Tohoku J. exp. Med., 1984, 142 (4), 399-407— Serum erythropoietin (ESF) levels and the numbers of marrow and blood erythroid progenitors (CFU-Es) of patients with chronic myeloproliferative disorders (CMPD) were studied simultaneously. The numbers of marrow and blood CFU-Es per $1 \times 10^{5}$ cells were normal or greatly elevated. There was an inverse correlation between the hemoglobin concentration and the serum ESF level in patients with chronic myelogenous leukemia when the hemoglobin concentration ranged from 9.0 to $13.0 \mathrm{~g} / 100$ ml. The serum ESF level was closely related to the hemoglobin concentration in CMPD and it was suggested that the negative feedback mechanism might operate in anemic patients with CMPD. chronic myeloproliferative disorders; fetal mouse liver cell assay; erythroid progenitor (CFU-E); erythropoietin (ESF)
\end{abstract}

A useful concept of the myeloproliferative disorders has been introduced by Dameshek (1951). Diseases considered as chronic myeloproliferative disorders (CMPD) are chronic myelogenous leukemia (CML), polycythemia vera (PV), primary myelofibrosis (PMF) and essential thrombocythemia (ET). The study of chromosomes and the X-linked isoenzyme system of glucose-6-phosphate dehydrogenase $(\mathrm{G} 6 \mathrm{PD})$ revealed that these disorders were clonal and involved pluripotent hemopoietic progenitors (Adamson et al. 1976; Fialkow et al. 1978, 1981; Jacobson et al. 1978). With the morphological examination of bone marrow and peripheral blood cells, the investigation of stem cells became essential, especially for the elucidation of pathophysiology of CMPD. Therefore, the number of reports on stem cells of CMPD is increasing. In contrast, there are very few reports concerning regulatory factors of hemopoiesis in CMPD. We will report

Received for publication, August 12, 1983. 
serum erythropoietin (ESF) levels using the fetal mouse liver cell (FMLC) bioassay and the numbers of marrow and blood CFU-Es of patients with CMPD and discuss the mechanism of hemopoiesis in CMPD.

\section{Materials and Methods}

Patients and controls. Subjects for the measurement of serum ESF levels were CML $(n=29), \mathrm{PV}(n=8)$, PMF $(n=6)$ and ET $(n=4)$. Normal controls were obtained from 13 healthy persons ( 8 males and 5 females). Subjects for the measurement of marrow and blood CFU-Es were CML $(n=14)$, PV $(n=7)$ and ET $(n=2)$, and CML $(n=15)$, PV $(n=$ 7), PMF ( $n=4)$ and ET $(n=2)$, respectively. All patients with a clinical diagnosis of CML had the Philadelphia chromosome. All patients with PV met the criteria of the National Polycythemia Vera Study Group. Aspiration of bone marrow in all patients with PMF was unsuccessful (dry tap), and various degrees of myelofibrosis were found in these patients by marrow biopsy. All patients with ET satisfied the criteria of Ozer et al. (1960) except erythrocyte levels. Marrow CFU-Es in 18 normal controls and blood CFU-Es in 11 other normal controls were measured (Table 1).

FMLC assay. Serum ESF levels were measured by FMLC bioassay in vitro according to a modified technique (Fukushima 1981) of Dunn et al. (1975). The assay method is as follows: Fetal liver cells obtained from dd-Y mouse embryos after 14 days of gestation were suspended in Eagle's Minimal Essential Medium (MEM, GIBCO) containing 5\% fetal calf serum (FCS, Flow). In a concentration of $1.0 \times 10^{6} \mathrm{cells} / \mathrm{ml}$, the culture tubes with 1 $\mathrm{ml}$ cell suspension were preincubated for $21-24 \mathrm{hr}$ at $37^{\circ} \mathrm{C}$ in humidified air with $5 \% \mathrm{CO}_{2}$. To cancel the influence of non-radioactive iron in test sera, cultured cells in each test tube were washed twice with sterile phosphate buffered saline (PBS). The cells were resuspended in $1 \mathrm{ml}$ of Eagle's MEM containing $5 \% \mathrm{FCS}$ and $0.5 \mu \mathrm{Ci}{ }^{59} \mathrm{Fe}$-ferric citrate (Radiochemical Centre, Amersham), which was bound to human transferrin (SIGMA) at $33 \%$ saturation in advance, and incubated for a further $4 \mathrm{hr}$. Heme was extracted according to the method of Teale (1959) and the radioactivity in aliquots of the solvent layer was determined in an autowell gamma counter. The cultures were set up in triplicate. Serum ESF levels were calculated by the formula of de Klerk et al. (1978). Sheep plasma ESF (Connaught, Step III) was used in this study throughout.

$C F U-E$ assay. The assay for CFU-Es was performed according to the plasma clot method by Terasawa et al. (1979). Buffy coat cells of bone marrow or peripheral blood were washed three times with Hank's MEM (GIBCO) and cultured in a cell concentration of $1 \times 10^{5}$ or $2 \times 10^{5}$ cells per clot. Culture media consisted of $20 \%$ FCS, $30 \% \alpha$-medium (Flow), 10\% ESF, 10\% beef embryo extract (GIBCO), 10\% deionized bovine serum albumin (SIGMA), $10 \%$ buffy coat cells, and $10 \%$ citrated AB type plasma. $0.4 \mathrm{ml}$ of the mixture was plated in the center of a $35 \mathrm{~mm} \times 10 \mathrm{~mm}$ Petri dish (Falcon Plastics) and 0.6 $\mathrm{ml}$ of $\alpha$-medium was placed around the plasma clot. The dish was incubated at $37^{\circ} \mathrm{C}$ in humidified air containing $5 \% \mathrm{CO}_{2}$ for 7 days. After the incubation, the clot was fixed in $5 \%$ glutaraldehyde and stained with benzidine and Giemsa solution. Colonies consisting of 8 or more cells which were benzidine positive were counted as erythroid colonies.

Student's $t$-test was used in all statistical evaluations.

\section{RESULTS}

The mean hemoglobin concentration was $12.3 \pm 0.3 \mathrm{~g} / 100 \mathrm{ml}$ (mean \pm s.E.) in all patients with CML and $11.8 \pm 0.7 \mathrm{~g} / 100 \mathrm{ml}$ in non-treated patients with CML and $12.5 \pm 0.4 \mathrm{~g} / 100 \mathrm{ml}$ in treated patients. It was $15.8 \pm 0.5 \mathrm{~g} / 100 \mathrm{ml}$ in patients with PV, $10.1 \pm 0.5 \mathrm{~g} / 100 \mathrm{ml}$ with PMF and $15.5 \pm 0.4 \mathrm{~g} / 100 \mathrm{ml}$ with ET (Table 1). 
TABLE 1. Subjects

\begin{tabular}{lcccc}
\hline & \multicolumn{1}{c}{ CML } & PV & PMF & ET \\
\hline Male & 17 & 1 & 2 & 3 \\
Female & 12 & 1 & 4 & 1 \\
Age & 41 & 58 & 61 & 55 \\
& $(17-58)$ & $(46-72)$ & $(53-72)$ & $(46-70)$ \\
WBC $\left(\times 10^{9} /\right.$ liter $)$ & 113 & 13 & 22 & 20 \\
& $(4-484)$ & $(6-30)$ & $(4-73)$ & $(16-24)$ \\
RBC $\left(\times 10^{12} /\right.$ liter $)$ & 4.09 & 6.71 & 3.67 & 6.10 \\
& $(2.98-4.73)$ & $(5.82-7.94)$ & $(2.76-5.84)$ & $(4.74-7.35)$ \\
Hb $(\mathrm{g} / 100 \mathrm{ml})$ & 12.3 & 15.8 & 10.1 & 15.5 \\
& $(8.2-14.3)$ & $(13.4-18.1)$ & $(8.9-12.7)$ & $(14.4-16.4)$ \\
PCV & 37.1 & 50.5 & 32.6 & 48.7 \\
& $(21.0-45.3)$ & $(41.4-55.3)$ & $(26.2-45.6)$ & $(45.1-52.1)$ \\
Platelet $\left(\times 10^{9} /\right.$ liter $)$ & 518 & 600 & 529 & 1224 \\
count & $(140-1423)$ & $(164-882)$ & $(85-922)$ & $(820-1622)$ \\
ESF $(\mathrm{mU} / \mathrm{ml})$ & 94.5 & 28.4 & 79.0 & 23.7 \\
& $(8.6-373.9)$ & $(9.5-61.6)$ & $(29.4-195.9)$ & $(2.8-60.8)$ \\
Therapy & $20 / 29$ & $4 / 8$ & $2 / 6$ & $2 / 4$ \\
& Busulfan & $32 \mathrm{p}$ & Splenectomy & Busulfan \\
& & & Prednisolone & \\
& $6-\mathrm{MP}$ & Busulfan & CPM & Pipobroman \\
\hline CFU-E $(\mathrm{BM})$ & 201 & 384 & & 237 \\
CFU-E $(\mathrm{PB})$ & $(53-433)$ & $(179-499)$ & & $(146-327)$ \\
& 152 & 0.6 & 152 & 68 \\
& $(9-477)$ & $(0-2)$ & $(36-283)$ & $(22-113)$ \\
\hline
\end{tabular}

$\mathrm{BM}=$ bone marrow, $\mathrm{PB}=$ peripheral blood, $\mathrm{CPM}=$ cyclophosphamide.

The numbers in parentheses show the ranges. Subjects in the measurement of marrow and blood CFU-Es were selected at random among subjects of ESF measurement.

Fig. 1 shows serum ESF levels of normal controls and patients with CMPD. The mean ( \pm s.E.) serum ESF level of normal controls was $46.8 \pm 7.7 \mathrm{mU} / \mathrm{ml}(n=$ 13). Serum ESF levels of patients with CML ranged from 8.6 to $373.9 \mathrm{mU} / \mathrm{ml}$, with a mean of $94.5 \pm 16.4 \mathrm{mU} / \mathrm{ml}$ and they were significantly higher than those of normal controls $(p<0.02)$. Serum ESF levels of non-treated and treated patients with $\mathrm{CML}$ were $99.0 \pm 26.9 \mathrm{mU} / \mathrm{ml}$ and $92.5 \pm 20.4 \mathrm{mU} / \mathrm{ml}$, respectively. There was no significant difference between them. Serum ESF levels ranged from 9.5 to $61.6 \mathrm{mU} / \mathrm{ml}$, with a mean of $28.4 \pm 5.3 \mathrm{mU} / \mathrm{ml}$ in $\mathrm{PV}, 29.4$ to $195.9 \mathrm{mU} / \mathrm{ml}$, with a mean of $79.0 \pm 23.4 \mathrm{mU} / \mathrm{ml}$ in $\mathrm{PMF}, 2.8$ to $60.8 \mathrm{mU} / \mathrm{ml}$, with a mean $23.7 \pm 11.5$ $\mathrm{mU} / \mathrm{ml}$ in ET. There was no significant difference between serum ESF levels of patients with PV, PMF and ET and those of normal controls.

Fig. 2 depicts the dose-response curves between ESF concentrations and the numbers of bone marrow CFU-Es of patients with PV and CML. In patients 


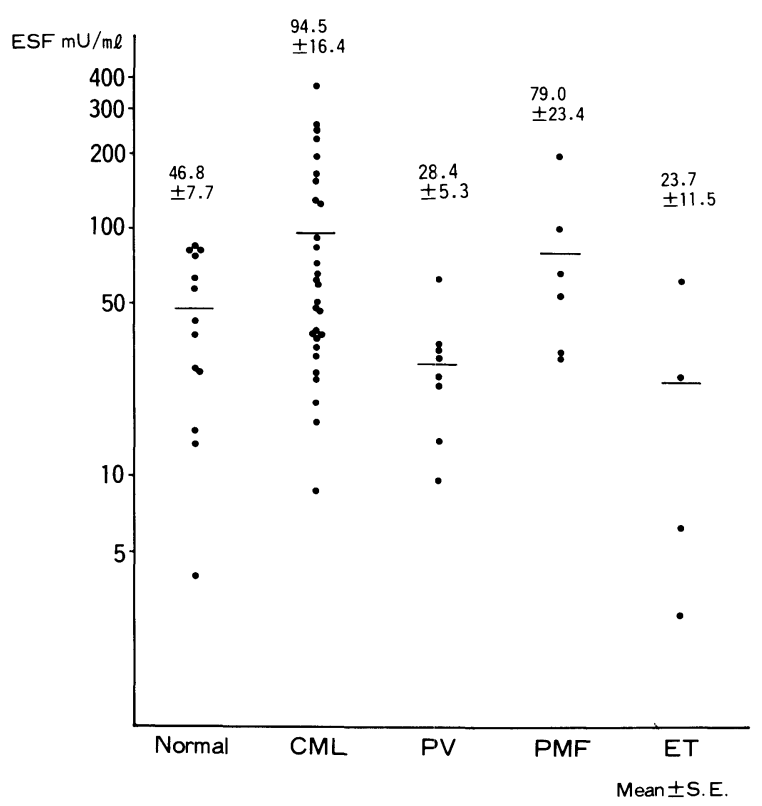

Fig. 1. Serum ESF levels using FMLC assay in normal controls and patients with CMPD.

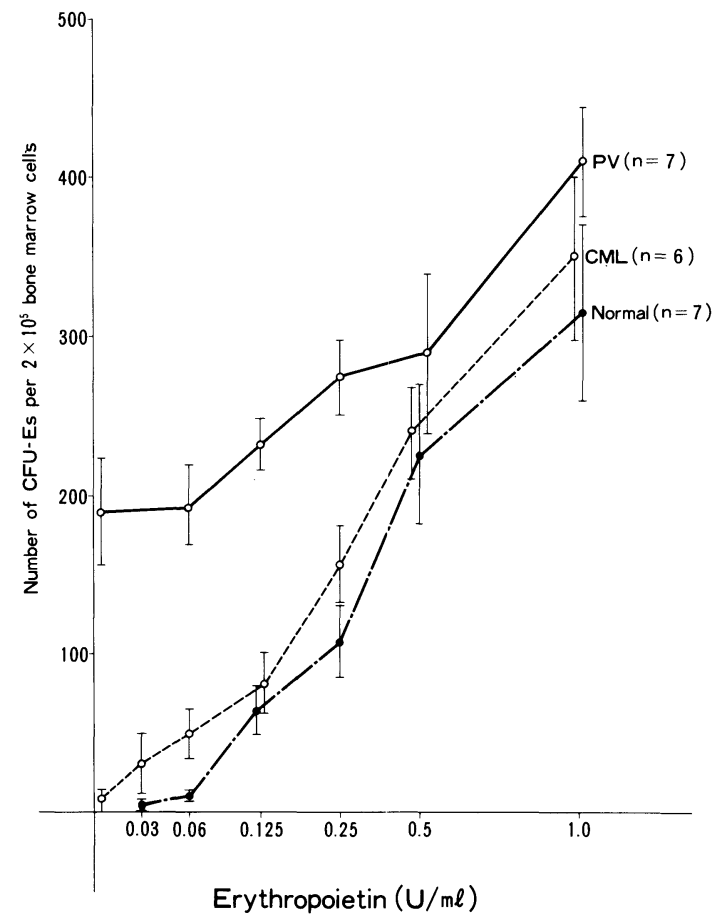

Fig. 2. The dose-response curves between ESF concentrations and the numbers of bone marrow CFU-Es of patients with PV and CML. Bars indicate s.E. of CFU-E numbers. 
with PV, many colonies were formed with low concentrations of ESF or without addition of ESF. The number of CFU-Es under $0.25 \mathrm{U} / \mathrm{ml}$ concentration of ESF in patients with $\mathrm{PV}$ was higher than that of normal controls $(p<0.01)$, and about $49 \%$ of marrow CFU-Es at $1.0 \mathrm{U} / \mathrm{ml}$ concentration of ESF was formed without addition of ESF. The number of marrow CFU-Es under $0.125 \mathrm{U} / \mathrm{ml}$ concentration of ESF in patients with CML was higher than that of normal controls $(p<$ $0.05)$.

The dose-response curves of 5 patients with ET and 4 patients with PMF varied widely at each case. The response of marrow CFU-Es to various concentrations of ESF of 2 patients with ET was similar to that of patients with PV, because many colonies were formed without addition of ESF, while in 3 other patients it was similar to that of normal controls. The response of peripheral blood CFU-Es to ESF of 2 patients with PMF was similar to that of marrow CFUEs to ESF of patients with PV, while in 2 other patients it was worse than that of normal controls. The optimal dose of erythropoietin is $1.0 \mathrm{U} / \mathrm{ml}$ in each disorder of CMPD.

Fig. 3 shows the numbers of CFU-Es per $1 \times 10^{5}$ bone marrow or peripheral blood cells of normal controls and patients with CMPD at $1.0 \mathrm{U} / \mathrm{ml}$ concentration of ESF. The number of marrow CFU-Es was $235 \pm 19 / 1 \times 10^{5}$ cells (mean \pm s.E.) in normal controls $(n=18)$ and blood CFU-Es were not detectable in any normal

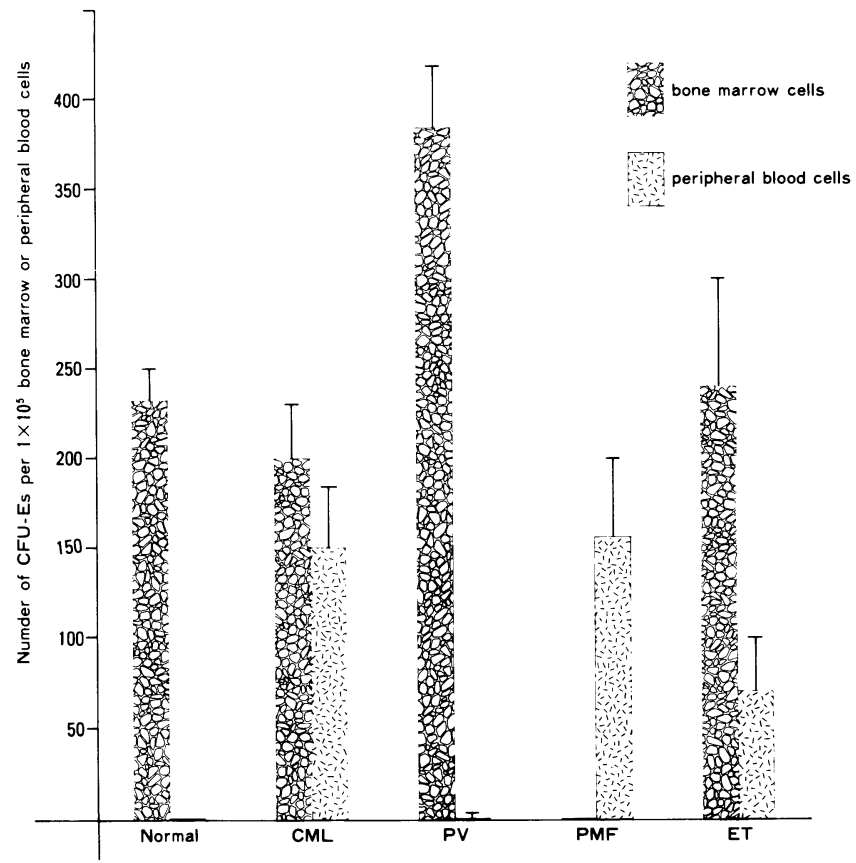

Fig. 3. The numbers of CFU-Es per $1 \times 10^{5}$ bone marrow or peripheral blood cells of normal controls and patients with CMPD at $1.0 \mathrm{U} / \mathrm{ml}$ concentrations of ESF. Bars indicate s.E. of CFU-E numbers. 
controls $(n=11)$. The number of marrow CFU-Es was $201 \pm 28 / 1 \times 10^{5}$ cells in patients with CML $(n=14)$ and the difference was not statistically significant in comparison with that of normal controls. The number of blood CFU-Es was $152 \pm 33 / 1 \times 10^{5}$ cells $(n=15)$ and was significantly higher than that of normal controls $(p<0.001)$. The numbers of marrow and blood CFU-Es of non-treated patients with CML were $238 \pm 38 / 1 \times 10^{5}$ cells $(n=6)$ and $247 \pm 54 / 1 \times 10^{5}$ cells $(n=6)$, respectively, and those of treated patients with CML were $173 \pm 38 / 1 \times 10^{5}$ cells $(n=8)$ and $88 \pm 24 / 1 \times 10^{5}$ cells $(n=9)$, respectively. The number of blood CFU-Es of treated patients was significantly lower than that of non-treated patients $(p<0.02)$. The number of marrow CFU-Es of treated patients was also lower than that of non-treated patients, though the difference was not statistically significant.

The number of marrow CFU-Es of patients with PV was $384 \pm 37 / 1 \times 10^{5}$ cells $(n=7)$ and was significantly higher than that of normal controls $(p<0.001)$. The number of blood CFU-Es of patients with PV was $0.6 \pm 0.3 / 1 \times 10^{5}$ cells $(n=7)$ and the difference was not significant in comparison with that of normal controls. The number of blood CFU-Es of patients with PMF was $152 \pm 45 / 1 \times 10^{5}$ cells $(n=4)$ and was significantly higher than that of normal controls $(p<0.001)$. The number of marrow CFU-Es of patients with ET was $237 \pm 64 / 1 \times 10^{5}$ cells $(n=2)$ and the difference was not statistically significant. The number of blood CFU-Es was $68 \pm 32 / 1 \times 10^{5}$ cells $(n=2)$ and was significantly higher than that of normal

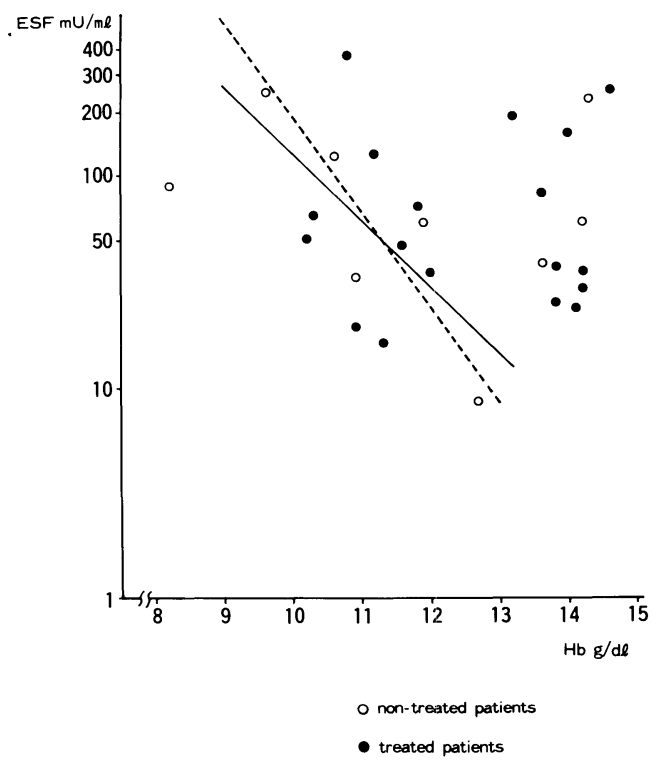

Fig. 4. Correlation between the serum ESF level and the hemoglobin concentration of patients with CML. In the range from 9.0 to $13.0 \mathrm{~g} /$ $100 \mathrm{ml}$ of the hemoglobin concentration, a significant negative correlation was found (solid line). Moreover, the correlation became closer in non-treated patients (dotted line). 
controls $(p<0.001)$.

In hemoglobin concentrations of all patients with CML studied, there was no correlation between the hemoglobin concentration and the logarithm of the serum ESF level (Fig. 4). But in the range from 9.0 to $13.0 \mathrm{~g} / 100 \mathrm{ml}$ of the hemoglobin concentration, a significant inverse correlation was found between the hemoglobin concentration and the logarithm of the serum ESF level $(Y=-0.72 X+12.10$, $r=-0.56, n=14, p<0.05)$. Moreover, when cases were restricted to non-treated patients, the correlation became closer $(Y=-1.01 X+15.26, r=-0.88, n=5, p<$ 0.05). In PV, PMF or ET, there was no correlation between the hemoglobin concentration and the logarithm of the serum ESF level. In CML or PV, there was no correlation between the serum ESF level and the number of marrow or blood CFU-Es.

\section{Discussion}

Since Dameshek (1951) defined the myeloproliferative disorders as a proliferative disorder of unknown etiology originated in bone marrow and extramedullary hemopoietic foci, the concept was generally accepted by most clinicians. Recently CMPD was regarded as a clonal disorder originated in diseased pluripotent hemopoietic stem cells. Thanks to technical progress, it is now possible to assay human pluripotent hemopoietic progenitors such as CFU-GEMM and CFUmix and the qualitative abnormality of human CFU-GEMM in PV was also reported (Fauser and Messner 1981). In this paper, we investigated marrow and blood CFU-Es as receptor cells of ESF.

Zanjani et al. (1977) showed that CFU-E of patients with PV was exquisitely sensitive to suboptimal levels of ESF and its pattern applied well in our cases without exception. The response of CFU-Es to ESF of some patients with ET or PMF was similar to that of patients with PV. These patients will develop PV.

Marrow and blood CFU-Es per $1 \times 10^{5}$ cells were normal or elevated in patients with CMPD. Therefore, it was suggested that the CFU-E compartment might be greatly increased (Fukuda 1982) considering the expanded hemopoietic foci in CMPD (Gunz and Baikie 1974). The hemoglobin concentrations and serum ESF levels of treated patients with CML was almost the same as those of non-treated patients, while blood CFU-Es of treated patients were significantly lower than those of non-treated patients. It might be due to busulfan (Brandt 1969; Fukuda 1982).

There are very few reports of ESF in CML, PMF and ET. But serum ESF levels have been investigated actively in PV, because they are available for the diagnosis of PV. There is no general agreement concerning ESF levels in PV. By using a method of radioimmunoassay, Garcia et al. (1982) reported that serum ESF levels in patients with PV were significantly lower than those of normal controls, while Koeffler and Goldwasser (1981) and Cotes (1982) reported that there was no significant difference between them. According to FMLC bioassay 
in vitro, de Klerk et al. (1981) reported that serum ESF levels in patients with PV were significantly lower than those of normal controls, while Napier and Janowska-Wieczorek (1981) reported that serum ESF levels were within lower limit of normal range or not detectable. According to the polycythemic mouse assay using concentrated plasma by Erslev et al. (1979), plasma ESF levels were less than $5 \mathrm{mU} / \mathrm{ml}$ in all cases of PV, while normal ESF levels ranged from 3.9 $\mathrm{mU} / \mathrm{ml}$ to $15.4 \mathrm{mU} / \mathrm{ml}$. Serum ESF levels of PV using our FMLC assay were lower, but there was no significant difference between those of patients with PV and those of normal controls.

It was supposed that the increase of CFU-Es in CMPD was originated in abnormal proliferation of pluripotent hemopoietic progenitors. Erythrocytosis is common in most patients with PV and ET. In contrast, anemia is common in most patients with CML and PMF. There are many unsolved problems in the genesis of anemia of CML and PMF.

It was assumed that serum ESF levels were closely correlated with hemoglobin concentrations in CMPD. When anemia becomes worse, the negative feedback mechanism between hemoglobin concentrations and serum ESF levels appears to be sustained. The assumption is supported by the following facts : 1) in polycythemic patients with PV and ET, serum ESF levels were lower than those of normal controls ; 2) serum ESF levels and hemoglobin concentrations were significantly inversely correlated in patients of CML with hemoglobin concentrations between 9.0 and $13.0 \mathrm{~g} / 100 \mathrm{ml}$; and 3) they were, however, not significantly correlated in patients with hemoglobin concentrations higher than $13.0 \mathrm{~g} / 100 \mathrm{ml}$. The reason of why the serum erythropoietin levels of patients with CML possessing a hemoglobin concentration higher than $13.0 \mathrm{~g} / 100 \mathrm{ml}$ were not low remains unclear. It might be regarded that the disease accompanied by anemia in nature needs more sufficient erythropoietin production to sustain the normal range of hemoglobin.

In conclusion, it is proved that serum ESF levels in CMPD are closely correlated with hemoglobin concentrations in each disorder. In disorders primarily resulting in erythrocytosis such as PV and ET, serum ESF levels are lower than those of normal controls. In disorders secondarily resulting in anemia such as CML and PMF, ESF production is stimulated by the negative feedback mechanism. It causes the elevation of serum ESF level and the red cell production seems to be stimulated.

\section{References}

1) Adamson, J.W., Fialkow, P.J., Murphy, S., Prchal, J.F. \& Steinmann, L. (1976) Polycythemia vera: Stem-cell and probable clonal origin of the disease. New Engl. J. Med., 295, 913-916.

2) Brandt, L. (1969) Differences in the proliferative activity of myelocytes from bone marrow, spleen and peripheral blood in chronic myeloid leukaemia. Scand. J. Haematol., 6, 105-112. 
3) Cotes, P.M. (1982) Immunoreactive erythropoietin in serum. I. Evidence for the validity of the assay method and the physiological relevance of estimates. Brit. $J$. Haematol., 50, 427-438.

4) Dameshek, W. (1951) Some speculations on the myeloproliferative syndromes. Blood, 6, 372-375.

5) de Klerk, G., Hart, A.A.M., Kruiswijk, C. \& Goudsmit, R. (1978) Modified method of erythropoietin (ESF) bioassay in vitro using mouse fetal liver cells. II. Measurement of ESF in human serum. Blood, 52, 569-577.

6) de Klerk, G., Rosengarten, P.C.J., Vet, R.J.W.M. \& Goudsmit, R. (1981) Serum erythropoietin (ESF) titers in polycythemia. Blood, 58, 1171-1174.

7) Dunn, C.D.R., Jarvis, J.H. \& Greenman, J.M. (1975) A quantitative bioassay for erythropoietin using mouse fetal liver cells. Exp. Hematol., 3, 65-78.

8) Erslev, A.J., Caro, J., Kansu, E., Miller, O. \& Cobbs, E. (1979) Plasma erythropoietin in polycythemia. Amer. J. Med., 66, 243-247.

9) Fauser, A.A. \& Messner, H.A. (1981) Pluripotent hemopoietic progenitors (CFUGEMM) in polycythemia vera : Analysis of erythropoietin requirement and proliferative activity. Blood, 58, 1224-1227.

10) Fiallow, P.J., Denman, A.M., Jacobson, R.J. \& Lowenthal, M.N. (1978) Chronic myelocytic leukemia: Origin of some lymphocytes from leukemic stem cells. $J$. Clin. Invest., 62, 815-823.

11) Fialkow, P.J., Faguet, G.B., Jacobson, R.J., Vaidya, K. \& Murphy, S. (1981) Evidence that essential thrombocythemia is a clonal disorder with origin in a multipotent stem cell. Blood, 58, 916-919.

12) Fukuda, M. (1982) Studies on hemopoietic stem cells. CFUc and CFUe in chronic myeloproliferative disorders. Akita $J$. Med., 8, 381-396. (in Japanese)

13) Fukushima, Y. (1981) Erythropoietin (ESF) bioassay in vitro using fetal mouse liver cells (FMLC). Acta haematol. jpn., 44, 1083-1088. (in Japanese)

14) Garcia, J.F., Ebbe, S.N., Hollander, L., Cutting, H.O., Miller, M.E. \& Cronkite, E.P. (1982) Radioimmunoassay of erythropoietin: Circulating levels in normal and polycythemic human beings. J. Lab. clin. Med., 99, 624-635.

15) Gunz, F. \& Baikie, A.G. (1974) Clinical and laboratory features of the myeloproliferative disorders. In : Leukemia, edited by F. Gunz \& A.G. Baikie, Grune \& Stratton, Inc, New York, pp. 377-430.

16) Jacobson, R.J., Salo, A. \& Fialkow, P.J. (1978) Agnogenic myeloid metaplasia: A clonal proliferation of hematopoietic stem cells with secondary myelofibrosis. Blood, 51, 189-194.

17) Koeffler, H.P. \& Goldwassser, E. (1981) Erythropoietin radioimmunoassay in evaluating patients with polycythemia. Ann. intern. Med., 94, 44-47

18) Napier, J.A.F. \& Janowska-Wieczorek, A. (1981) Erythropoietin measurements in the differential diagnosis of polycythaemia. Brit. J. Haematol., 48, 393-401.

19) Ozer, FL., Truax, W.E., Miesch, D.C. \& Levin, W.C. (1960) Primary hemorrhagic thrombocythemia. Amer. J. Med., 28, 807-823.

20) Teale, F.W.J. (1959) Cleavage of the haem-protein link by acid methylethylketone. Bichim. biophys. Acta, 35, 543.

21) Terasawa, T., Kimura, H., Maruyama, W. \& Kasai, S. (1979) An improved assay method for erythrocytic colony forming units in murine and human bone marrow. Acta haematol. jpn., 42, 72-78.

22) Zanjani, E.D., Lutton, J.D., Hoffman, R. \& Wasserman, L.R. (1977) Erythroid colony formation by polycythemia vera bone marrow in vitro. Dependence on erythropoietin. J. clin. Invest., 59, 841-848. 